\title{
Incidence of hip fracture in Kermanshah, Iran
}

\author{
Mandana Beyranvand • Goergee Mohammadi
}

Received: 4 April 2009 /Accepted: 1 September 2009/Published online: 2 October 2009

(C) The Author(s) 2009. This article is published with open access at Springerlink.com

\begin{abstract}
Summary The aim of this study was to estimate the incidence of hip fracture in Kermanshah, Iran. 161 cases ( 88 men and 73 women) were recorded. The annual agestandardized incidence rates were $181.1 / 100,000$ in men and 214.6/100,000 in women. Incidence rate of hip fracture was less than in Western countries.

Introduction Hip fracture is the most serious complication of osteoporosis, the most common metabolic bone disease worldwide. The incidence of hip fracture in the elderly patients varies in different areas. The aim of this study was to estimate the incidence rate of hip fracture in Kermanshah, Iran.

Materials and methods All cases of hip fracture patients who aged 50 years or more admitted in six referral orthopedic hospitals in Kermanshah from May 21, 2007 to May 21, 2008 were studied. The age- and sex-specific incidence rates of hip fracture per 100,000 persons were calculated using the population data from the last national census in Iran, 2007.

Results A total of 161 cases of hip fracture (88 men and 73 women) were recorded. The annual age-standardized incidence rates were $181.1 / 100,000$ in men and 214.6/ 100,000 in women.

The female to male ratio of hip fracture incidence was 1.18 .
\end{abstract}

\footnotetext{
M. Beyranvand $(\square)$

AJA University of Medical Science,

Etemadzade St. Fatemi Ave.,

Tehran, Iran

e-mail: Beiran_r@yahoo.com

G. Mohammadi

Kermanshah University of Medical Science,

Kermanshah, Iran
}

Conclusion We found a relatively low incidence of hip fracture in Iran than in Western countries, which is mostly due to the lower rate in women. This is probably related to the different lifestyle factors in different societies.

Keywords Hip fracture · Incidence $\cdot$ Iran $\cdot$ Kermanshah . Osteoporosis

\section{Introduction}

Osteoporosis is the most common metabolic bone disease in the world. Hip fracture is considered as the most serious complication of osteoporosis. There are substantial interracial differences between hip fracture incidence, and many studies have implicated that this problem is higher in Western than Asian countries [17]. As to our knowledge, limited studies have been performed to measure the incidence of hip fracture in Iran [1-3]. The aim of this study was to estimate the incidence of hip fracture in Kermanshah, Iran. We also described age- and sex-specific incidence rates of low and high trauma fracture, type and place of the fracture, number of children in women, seasonal variations, and in-hospital mortality.

\section{Materials and methods}

Kermanshah, the capital city of Kermanshah province, is located in the west of Iran. According to the national census of 2007 , the population of Kermanshah city was about 800,090 and $14.4 \%$ of the population was aged $\geq 50$ years. There are six referral orthopedic hospitals in Kermanshah. We collected our data from these hospitals. 
In this prospective study, all cases of hip fracture aged 50 years or more admitted in these orthopedic hospitals during a one-year period from May 21, 2007 to May 21, 2008 were included. Hip fracture is defined as clinical and radiological evidence of fracture of the proximal femur (ICD-10: S72.0). The patients or a family member were interviewed to collect information including age, gender, originality, number of children in women, previous hip fracture, date, cause, and place of incident. The type of fracture (femoral neck, intertrochanteric) was verified by inspection of the X-rays. Mortality rate of the patients during hospitalization was also determined. According to their history, discharged sheets, and X-rays, the following patients were excluded:

1. Nonresidents treated in Kermanshah.

2. Fractures resulting from pathologic conditions.

3. Patients admitted for a complication or with a diagnosis of previous hip fracture.

4. Femoral shaft and/or supracondylar fractures.

The age-specific incidence rates of hip fracture per 100,000 persons were calculated for each sex and 10-year age group, by dividing the numbers of hip fractures recorded during the study period by the sum of the persons aged $\geq 50$ years. The age-specific rates in men and women aged equal to or more than 50 years were then applied to the 2,000 US white populations to calculate age-adjusted rates of hip fracture. For this purpose, the direct method of standardization was used. Other data was analyzed using the SPSS software for Windows (SPSS Inc., Chicago, IL, USA) and $P$ values less than 0.05 were considered statistically significant.

\section{Results}

A total number of 161 new cases of hip fracture (88 men, 73 women) occurred in people age $\geq 50$ years during the study period. The mean age $( \pm \mathrm{SD})$ of patients was 72.27 $( \pm 11.11)$ years (range, 50 to 94 year). The mean age $( \pm S D)$ for males and females were $71.41( \pm 11.88)$ and 73.46 $( \pm 9.91)$ years, respectively.

The crude annual incidence rates of hip fracture were 150.4/100,000 (95\% confidence interval (CI): 120.7-185.3) in men and 131.7/100,000 (95\% CI: 103.3-165.6) in women. The annual age-standardized incidence rates were $181.1 / 100,000$ in men and 214.6/100,000 in women. The female to male ratio of hip fracture incidence was 1.18 . The age- and sex-specific incidence rates of hip fracture per 100,000 women and men $\geq 50$ years of age are presented in Table 1.

As shown in Table 1, the rate of hip fracture in men was more than in women in the two extremes of age (50-59 age group and the over 80 age group), and the difference was significant in $50-59$ age group $(P=0.024)$. In both sexes, the rates increased with increasing age.

We had information about the cause and place of incidences in 143 patients. In $119(83.2 \%)$ cases, low trauma (fall-induced) was the case of fracture and 24 $(16.8 \%)$ cases had suffered high trauma. In low-trauma fracture group, $61(51.3 \%)$ and $58(48.7 \%)$ cases were men and women, respectively. The mean age $( \pm \mathrm{SD})$ in this group was $76.35( \pm 8.7)$ years. The mean age $( \pm \mathrm{SD})$ for men and women were $74.79( \pm 9.54)$ and $74.02( \pm 9.65)$ years, respectively. Most of low-trauma fractures were sustained inhouse (109 cases, 88.3\%).

In high-trauma fracture group, there were 20 men and four women with a mean age $( \pm \mathrm{SD})$ of $60.64( \pm 11.24)$ years. The mean age $( \pm \mathrm{SD})$ for men and women were 58.8 $( \pm 9.54)$ and $68( \pm 10.22)$ years, respectively. Eighteen patients sustained the trauma outside of their house.

In our female patients, $67(90.6 \%)$ cases had more than two children with a mean of 5.5 children.

The incidence of fracture was nearly similar in winter $(33.6 \%)$ and spring (32.9\%), and the lowest incidence was in summer $(11.4 \%)$. The rate of intertrochanteric fracture (101 subject, 62.9\%) was significantly higher than femoral neck fracture (60 cases, $37.1 \%$ ); $P<0.001$

In-hospital mortality during the study period was $11.2 \%$ (18 cases: 12 men and six women).

\section{Discussion}

In this study, the standardized incidence rates of hip fracture were 181.1/100,000 in men and 214.6/100,000 in women. These rates were lower than those observed in Western countries, which is mostly due to the lower rate of fractures in women. These results in comparison to the previous studies in Iran were nearly similar to the results of Valizadeh et al. [2], but more than those reported by Moayyeri et al. [3]. This difference may be due to the duration of the latter study. Moayyeri et al. [3] collected their data in a limited time frame and did not consider the effect of seasonal variation on the incidence of hip fracture. But our study and the study of Valizadeh et al. [2] were carried out in 1-year period.

Some potential differences may be responsible for the racial difference in osteoporosis-related fractures including bone mineral density (BMD), fall events, bone geometry, and strength [8].

A study from Larigani et al. in 2003 has demonstrated that BMD in Iranian women is similar or lower than Western women [9]. The result of early studies in other Asian countries were similar to this article, but in later studies, the BMD values at both the hip and spine were 
Table 1 The age- and sex-specific incidence rate of hip fracture per 100,000 during 2007-2008 in Kermanshah, Iran

\begin{tabular}{|c|c|c|c|c|c|c|c|c|c|}
\hline \multirow[t]{2}{*}{ Age group } & \multicolumn{4}{|c|}{ Female } & \multicolumn{4}{|c|}{ Male } & \multirow[t]{2}{*}{$\mathrm{F} / \mathrm{M}$ ratio } \\
\hline & No. & Population & Rate & $95 \% \mathrm{CI}$ & No. & Population & Rate & $95 \% \mathrm{CI}$ & \\
\hline $50-59$ & 7 & 28,878 & 24.2 & $9.7-49.9$ & 18 & 29,906 & 60.2 & $35.7-95.1$ & 0.39 \\
\hline $60-69$ & 14 & 14,074 & 99.5 & $54.4-166.8$ & 12 & 14,397 & 83.4 & $43.1-45.6$ & 1.16 \\
\hline $70-79$ & 29 & 9,189 & 315.6 & $211.5-452.9$ & 27 & 10,556 & 255.8 & $168.6-371.9$ & 1.07 \\
\hline$\geq 80$ & 23 & 3,412 & 703.8 & $446.7-1054.2$ & 31 & 3,794 & 52.4 & $579.8-1207.7$ & 0.74 \\
\hline Total & 73 & 55,553 & 131.7 & $103.3-165.6$ & 88 & 58,653 & 150.4 & $120.7-185.3$ & 0.85 \\
\hline
\end{tabular}

No number, $C I$ confidence interval, $F$ female, $M$ male

similar to those in Caucasians after adjustment for height and weight [10-12].Thus, the lower incidence of hip fracture in Asian population may not only due to difference in BMD, but to other biomechanical factors, such as bone geometry and strength as well [8]. Asians have smaller bone areas compared with Caucasians and bone geometry parameters including various lengths (hip axis length, femoral neck diameter, and length) are also significantly shorter in Asians than Caucasian women [10, 12-14].

Falling is another risk factor for osteoporosis-related fracture. A study about characteristics of fall leading to hip fractures in Iranian population showed that several potential environmental factors could be important in preventing fallinduced fractures. These consisted of family support of elder people and coverage of passageways with some kinds of carpets [15]. But in developed countries, most elder individuals live alone and apart from their family members. They have to be mobile to meet the daily requirements and take part in different social activities, which boosts the falling rate causing hip fracture [2].

The rate of hip fracture rises with increasing age. According to the World Health Organization (WHO) report in 2006, life expectancy in Iran is lower than Western countries. For example, life expectancy in Iran and the US for both sexes is 71.1 and 78 , respectively. Thus, one possibility to explain the lower rate of hip fracture in Iran is lower life expectancy in comparison with Western countries.

The obtained female to male ratio of hip fracture incidence was lower than in Western countries, which is similar to previous studies in Iran $[1,2]$. The higher rate of fracture in men than women in 50-59 age group was statistically significant. In Iran, men usually engage, more than women, in social and recreational activities. This social pattern can increase trauma and falling possibilities among men. In our study, 24 patients had high trauma and 20 cases of them were men and most of them (16 cases) sustained the trauma outside of their home. But in lowtrauma group, the percentage of men $(51 \%)$ and women $(49 \%)$ was nearly similar and most of them $(88.3 \%)$ sustained the injury at home.
Some reports suggest that breast-feeding and multiparity may reduce the risk of hip fracture [16-20]. A study in Iran about the relationship between number of pregnancies and BMD reported that there were statistically significant differences in lactation period, number of children, and femoral BMD in women with more than two children in comparison with women who had $0-2$ children [21]. In our study, also most of the women $(90.4 \%)$ were multipare. This could be the result of not using contraceptive methods among Iranian women in the past decades. Therefore, multiparity in Iranian senile women may be a protective factor that can partly explain the lower rate of hip fracture.

According to the national census in 2007, the population of men and women aged $\geq 50$ years in Iran was 4,964,432 and 4,800,012, respectively. However, in Western countries, such as the US, the population of women aged $\geq 50$ years is higher than men of the same age group. According to the report of the United States Census Bureau in 2000 , the population of white males and females was $29,321,409$ and $35,351,093$, respectively. In our study, in all age groups, the population of men was more than women. This may be one possibility that explains the low rate of hip fracture in our women.

According to WHO report in 2006, life expectancy in Iranian men and women is 68.9 and 73.4 years, respectively. With respect to the high rate of hip fracture in our male patients, this means that other factors such as difference in lifestyle factors between men and women may explain this paradox.

The rates of fracture in spring and winter were $66.5 \%$ that emphasizes on vitamin D and calcium supplementation, especially in low-light seasons of the year.

In this population, there was a higher rate of intertrochanteric fracture than femoral neck ones, which is similar to another study in Iran [1]. Since mortality, morbidity, and costs of intertrochanteric fracture are higher than those of neck fracture, should we not treat patients with intertrochantric osteoporosis with more attention?

In-hospital mortality in our patients (11.3\%) is similar to international figures [22]. 
The limitation of this study was that about $10 \%$ of patients left the hospitals before the interview. Therefore, $10 \%$ of the data about place and cause of fracture was lacked, and statistical analysis was done on the available data.

In conclusion, we found a relatively low incidence of osteoporotic hip fracture in Kermanshah, Iran than in Western countries, which is mostly due to the lower rate in women. This may be due to several indirect factors including population ratio difference, life expectancy, family support, life habit, carpet flooring, multiparity, breast-feeding, and bone geometric factors. The high rate of hip fracture among our men shows us that osteoporosis in men is as important as women. To evaluate the effect of indirect factors on the incidence of hip fracture in Iran, further investigations are required.

Acknowledgment We would like to thank the head nurses of orthopedic hospitals for their cooperation in collecting data and Dr. S. Mazloomzadeh and Dr. M. Rezai for data analysis. We also thank Dr. A. Khorramipur for editing the manuscript.

\section{Conflicts of interest None.}

Open Access This article is distributed under the terms of the Creative Commons Attribution Noncommercial License which permits any noncommercial use, distribution, and reproduction in any medium, provided the original author(s) and source are credited.

\section{References}

1. Soveid M, Serati AR, Masoompoor M (2005) Incidence of hip fracture in Shiraz, Iran. Osteoporos Int 16:1412-1416

2. Valizadeh M, Mazloomzadeh S, Azizi R (2008) Epidemiology of hip fractures in Zanjan, Iran. Arch Osteoporos 3:1-5

3. Moayyeri A, Soltani A, Larijani B et al (2006) Epidemiology of hip fracture in Iran. Osteoporos Int 17:1252-1257

4. Lau EM, Lee JK, Suriwongpasial P et al (2001) The incidence of hip fracture in four Asian countries: the Asian Osteoporosis Study (AOS). Osteoporos Int 12:239-243
5. Memon A, Pospula WM, Tanatawy AY et al (1998) Incidence of hip fracture in Kuwait. Int J Epidemiol 27:860-865

6. Xu L, Lu A, Zhao X et al (1996) Very low rates of hip fracture Beijing, People's Republic of China: the Beijing Osteoporosis Project. Am J Epidemiol 144:901-907

7. Rowe SM, Yoon TR, Rayang DH (1993) An epidemiological study of hip fracture in Honam, Korea. Int Orthop 17:139-143

8. Cooper C (1996) Femoral neck bone density and fracture risk. Osteoporos Int supp 3:S24-S26

9. Larijani B, Soltani A, Pajouhi M et al (2003) Bone mineral density variation in 20 to 69 -years-old population of Tehran-Iran (in Persian). Iran South Med J 1:41-49

10. Lau EMC (1997) Epidemiology of osteoporosis in urbanized Asian populations. Osteoporos Int 7(Supp. 3):S91-S95

11. Lau EMC (1996) The epidemiology of hip fracture in Asia: an update. Osteoporos Int supp 3:S19-S23

12. Seeman E (1998) Growth in bone mass size-are racial and gender differences in bone mineral density more apparent than real? J Clin Endocrinol Metab 5:1414-1419

13. Geusens P (1996) Geometric characteristics of the proximal femur and hip fracture risk. Osteoporos Int 6(Supp. 3):27-30

14. Lei SF, Chen Y, Xiong DH et al (2006) Ethnic difference in osteoporosis-related phenotypes and its potential underlying genetic determination. J Musculoskelet Neuronal Interact 6(1):3646

15. Abolhassani F, Moayyeri A, Naghavi M et al (2006) Incidence and characteristics of falls leading to hip fracture in Iranian population. Bone 39:408-413

16. Huo D, Lauderdale DS et al (2003) Influence of reproductive factors on hip fracture risk in Chinese women. Osteoporos Int 14:694-700

17. Cumming RG, Klineberg R (1993) Breastfeeding and other reprodactive factors and the risk of hip fracture in elderly women. Int J Epidemiol 22:684-691

18. Cure C, Ramirez P, Teran E (2002) Bone mass peak in multiparity and reduced risk of bone fractures in menopause. Int $\mathrm{J}$ Gynecol Obstet 76:285-291

19. Smith RW (1980) Dietary and hormonal factor in bone loss. Henry ford Hosp Med J 28:171-181

20. Fox KM, Magaziner J, Shervin R et al (1993) Reproductive correlates of bone mass in elderly women. J Bone Miner Res 8:901-908

21. Biranvand M, Rajaee AR, Yoosef-Ghahari B et al (2004) The relationship between number of pregnancy and bone density (in Persian). Behbood 8:10-16

22. Jiang HX, Majumdar SR, Dick DA et al (2005) Development and initial validation of a risk score for predicting with hip fracture. J Bone Miner Res 20:494-500 